\title{
The Correlation between Class I, II, III Dental and Skeletal Malocclusion in Ethnic Javanese: A Cross sectional Study
}

\author{
I Gusti Aju Wahju Ardani', Danitya W. Heswari², Alida Alida ${ }^{1}$ \\ ${ }^{1}$ Department of Orthodontics, Faculty of Dental Medicine, Universitas Airlangga, ${ }^{2}$ Faculty of Dental Medicine, Universitas Airlangga, Surabaya, Indonesia
}

\section{Abstract}

\begin{abstract}
Aim: This study aimed to analyze the correlations between skeletal and dental Class I, II, III malocclusion and the association between molar relation and skeletal classes among Javanese people at Universitas Airlangga Dental Hospital, Surabaya, Indonesia. Materials and Methods: An observational analysis study with cross-sectional and total sampling method was conducted. A minimum sample size is determined by Lameshow's formula. Samples $(n=132)$ were collected from Airlangga University Dental Hospital. Study models were taken and assessed for the overjet and overbite values and molar relationship according to Angle classification. The lateral cephalography was analyzed to obtain Sella-Nasion-A point (SNA), Sella-Nasion-B point (SNB), A point-Nasion-B point (ANB), Wits, upper incisor-Nasion-A point (U1-NA), and lower incisor-Nasion-B point (L1-NB). The descriptive statistics were performed for calculating the mean and standard deviation. Pearson's correlation test and Spearman's rho test were applied to determine the possible correlation between skeletal and dental measurements $(P<0.05)$. Results: There was an increase of U1-NA and L1-NB in all three classes. On the contrary, there was a decrease of SNB in Class II malocclusion. Class III malocclusion showed an increase of SNB and a decrease of SNA. There is a correlation between skeletal and dental measurements in all three classes. The association between molar relations and skeletal classes in this experiment is intermediate. Conclusion: There was a correlation between skeletal and dental conditions that can exacerbate malocclusion in ethnic Javanese.
\end{abstract}

Keywords: Dental, Ethnic Javanese, Malocclusion, Molar Relation, Skeletal

\section{INTRODUCTION}

The high prevalence puts malocclusion as a public health problem and becomes the third highest priority for oral health world wide. ${ }^{[1]}$ In Indonesia, malocclusion is ranked as the most prevalent oral health problem. ${ }^{[2]}$ Malocclusion has multifactorial causes classified into the general factors and the local factors. General factors cover hereditary, congenital abnormalities, environment, and trauma, whereas local factors cover the number and the shape of teeth anomalies, premature loss, and caries. ${ }^{[3]}$

Malocclusion is not only caused by the dental condition but also it is affected by the skeletal condition. The normal pattern of skeletal malocclusion is Class I and characterized by a straight facial profile where the maxilla and the mandible are harmonized. The pattern of Class II skeletal malocclusion is characterized by a

\begin{tabular}{|l|l|}
\hline \multicolumn{2}{|c|}{ Access this article online } \\
\hline Quick Response Code: & Website: \\
\hline & www.jioh.org \\
\cline { 2 - 2 } & \\
\hline
\end{tabular}

convex facial profile and it is probably caused by the retruded mandible, the protrusion of the maxilla, or a combination of both. ${ }^{[4-6]}$ Moreover, the patterns of Class III skeletal malocclusion are characterized by a concave facial profile, which may be because of mandibular protrusion, maxillary retrusion, or a combination of both. ${ }^{[7]}$ Our previous study showed that the most common maxillary arch form was square in malocclusion Class I, tapered in Class II and Class III. Meanwhile, the most common arch form found was square in all three classes of malocclusion, Class I,

Address for correspondence: Dr. I Gusti Aju Wahju Ardani, DDS., M.SC. Department of Orthodontics, Faculty of Dental Medicine, Universitas Airlangga, Jalan Mayjen Prof. Dr. Moestopo 47 Surabaya, Surabaya, East Java, Indonesia. E-mail: wahju_ardani@fkg.unair.ac.id

This is an open access journal, and articles are distributed under the terms of the Creative Commons Attribution-NonCommercial-ShareAlike 4.0 License, which allows others to remix, tweak, and build upon the work non-commercially, as long as appropriate credit is given and the new creations are licensed under the identical terms.

For reprints contact: reprints@medknow.com

How to cite this article: Ardani IG, Heswari DW, Alida A. The correlation between Class I, II, III dental and skeletal malocclusion in ethnic Javanese: A cross sectional study. J Int Oral Health 2020; $12: 248-52$. 
Class II, and Class III, in the mandibular arch form among ethnic Javanese. ${ }^{[8]}$

Meanwhile, the relationship between dental and skeletal characteristics has been long debated in the field of orthodontics. Some studies say that dental condition is strongly affected by the skeletal of the face. The local changes in the tooth can have a limited effect on the discrepancy between the relationship of the maxilla and the lower jaw. According to Al-Jaba and Aldrees, ${ }^{[9]}$ changes in the relative position of nasal to points $A$ and $B$ can affect the value of $A$ point-Nasion-B point (ANB), meaning that the value of ANB does not always correspond to its dental state. The type of molar relationship found in Class III skeletal malocclusion is Class I, whereas in the study conducted by Zhou et al. ${ }^{[10]} 85 \%$ of individuals with Class III skeletal malocclusion have a molar relation according to their skeletal conditions. A study by Zupancic et al.,,$^{[11]}$ found that overjet cannot describe the skeletal state in Class I and III malocclusion, but it can be a good predictor of skeletal conditions in Class II division 1 malocclusion. Furthermore, a study by Ardani et al. in Javanese population showed that Class II skeletal malocclusion with anteroposterior skeletal discrepancies are characterized by a large ANB reflecting the malrelationship between the maxilla and mandible. Class II skeletal malocclusion has an increased ANB, mostly not by the rising Sella-Nasion-A point (SNA) but by the declining Sella-Nasion-B point (SNB) ${ }^{[12,13]}$

Furthermore, the skeletal and the dental correlation are very important to understand because it is very essential in determining the right diagnosis and treatment plan. Thus, this study aimed to investigate the correlation between skeletal and dental characteristics in Class I, II, and III malocclusion in ethnic Javanese patients at Universitas Airlangga Dental Hospital, Surabaya, Indonesia.

\section{Materials and Methods}

\section{Study design and sampling criteria}

This was an observational analysis study with crosssectional and blind total sampling methods. A minimum sample size is determined by Lameshow's formula. One hundred-thirty-two samples were collected from Airlangga University Dental Hospital. All informed consents were obtained from all participants. The inclusion criteria of the study were as follows: patients with diagnosis of Class I, II, and III skeletal malocclusion, patient who had never undergone any orthodontic treatment, all study models and lateral cephalometric radiograph that were in good condition, all permanent and maxillary permanent teeth from the first molar to the first molar that were erupted, and the patients from Javanese background. The exclusion criteria of the study were as follows: patients with systemic diseases, craniofacial malformations, cleft lip and palate, facial asymmetry, missing teeth, supernumerary teeth, and impacted teeth.

\section{Observational parameters}

In this study, patients' models and lateral cephalograph were used. Samples with malocclusion were classified based on the value of ANB. Class I had the range of ANB from $2^{\circ}$ to $4^{\circ}$, Class II $>4^{\circ}$, and Class III $<1^{\circ}$.

Study models of the patients were taken and assessed for the value of overjet and overbite using a ruler and a digital Vernier Caliper ( $0.01 \mathrm{~mm}$ of accuracy). Overjet was measured from the horizontal distance of upper incisor incisive to the labial surface of lower incisor incisive. Overbite was measured from the vertical distance of the upper incisor incisive to the lower incisor incisive.

Along with ANB value, samples were also assessed for the existing of molar relationship according to Angle classification. The lateral cephalograph was then analyzed by using an automatic computed digital Morpheus (Sinbong 1-ro, Suji-gu, Youngin-si, Gyeonggi-do, Korea) software (Morpheus, Sinbong 1-ro, Suji-gu, Youngin-si, Gyeonggi-do, Korea) to obtain the value of SNA, SNB,

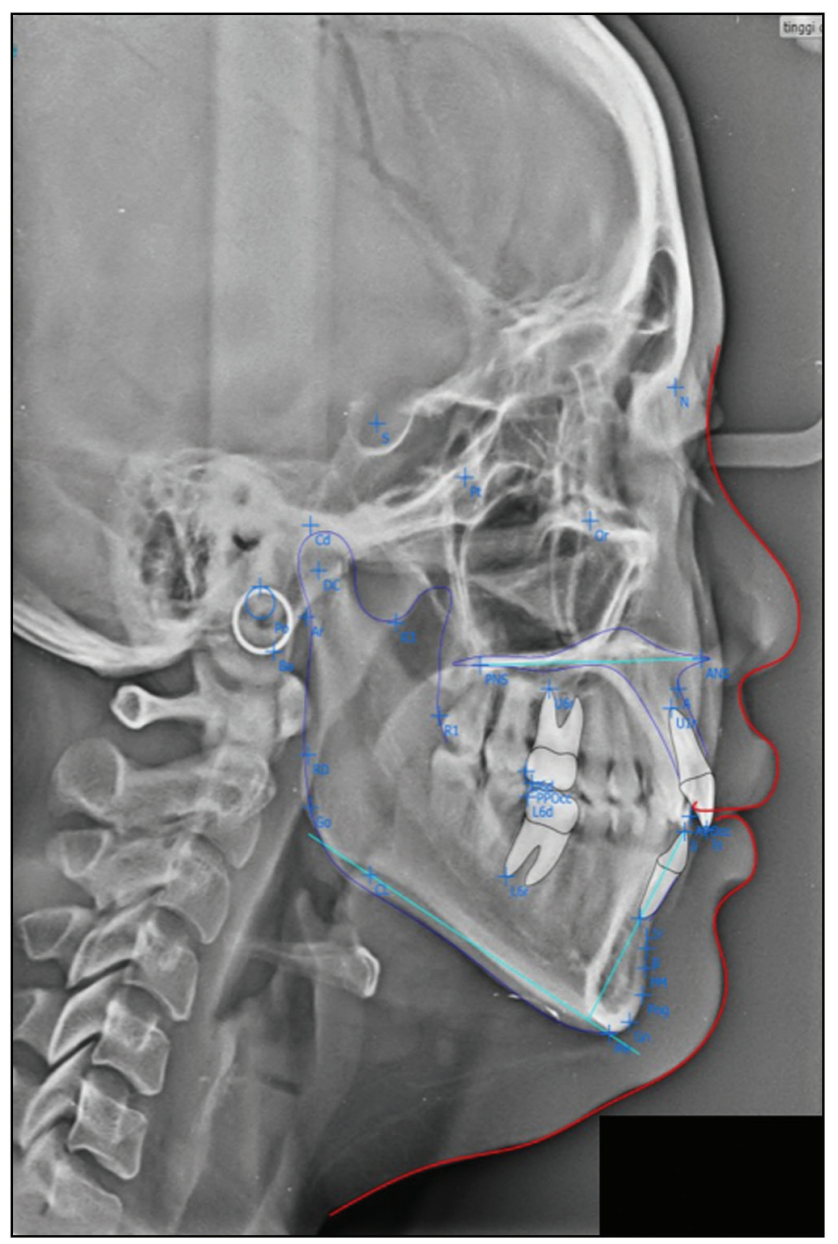

Figure 1: An example of the cephalometry analysis of malocclusion in ethnic Javanese patient 
ANB, Wits, upper incisor-Nasion-A point (U1-NA), and lower incisor-Nasion-B point (L1-NB) [Figure 1]. There was only one observer and a total of 132 samples were recorded with no drop or withdrawal was noted.

\section{Statistical analysis}

All data were analyzed performed using the Statistical Package for the Social Sciences software, version 20.0 (IBM, Chicago, IL). Descriptive statistics were applied for the calculation of mean, standard deviation, maximum, and minimum. Pearson's correlation test and Spearman's rho test were used to determine the possible correlation between skeletal and dental measurements $(P<0.05)$. Cohen's Kappa test was applied to determine the level of agreement between class of molar relation and skeletal $(P<0.05)$.

\section{RESULTS}

A total of 132 samples comprising 37 men and 95 women (ranging from 12 to 30 years old) who fulfilled the criteria were included in this study. They were classified into three classes according to ANB: 51 samples of Class I with ANB angle of $2^{\circ}$ to $3.5^{\circ}, 50$ samples of Class II with ANB angle of $5^{\circ}$ to $13^{\circ}$, and 31 samples of Class III with angle of $\mathrm{ANB}-1^{\circ}$ to $-10^{\circ}$ comprising 37 male patients and 95 female patients aged between 12 and 30 years. In Class I skeletal malocclusion [Table 1], there is a correlation between SNA and U1-NA $(\mathrm{mm})(r=-0.299, P=0.033$; $P<0.05)$, SNB and U1-NA $(\mathrm{mm})(r=-0.292, P=0.037$; $P<0.05)$, ANB and L1-NB (mm) $(r=0.358, P=0.01$; $P<0.05$ ). However, in Class II skeletal malocclusion [Table 2], there is a correlation between Wits and U1-NA $\left(^{\circ}\right)(r=-0.308, P=0.03 ; P<0.05)$, ANB and U1-NA (mm) $(r=-0.406, P=0.003)$, ANB and U1-NA $\left(^{\circ}\right)$ $(r=-0.328, P=0.02 ; P<0.05)$. Moreover, in Class III skeletal malocclusion [Table 3], ANB is correlated with overjet $(r=0.547, P=0.001 ; P<0.05)$, overbite $(r=0.462$, $P=0.009 ; P<0.05), \mathrm{U} 1-\mathrm{NA}\left({ }^{\circ}\right)(r=-0.518, P=0.003$; $P<0.05)$, and L1-NB $\left(^{\circ}\right)(r=0.407, P=0.023 ; P<0.05)$. It is found that there is also a correlation between SNA and U1-NA $(\mathrm{mm})(r=-0.368, P=0.042 ; P<0.05)$, SNA

\begin{tabular}{lc}
\hline $\begin{array}{l}\text { Table 1: The descriptive } \\
\text { malocclusion }\end{array}$ & \\
\hline Measurement & Mean \pm standard deviation \\
\hline Overjet $(\mathrm{mm})$ & $3.85 \pm 2.48$ \\
Overbite $(\mathrm{mm})$ & $2.96 \pm 1.74$ \\
U1-NA distance $(\mathrm{mm})$ & $9.25 \pm 3.67$ \\
U1-NA inclination $\left(^{\circ}\right)$ & $30.46 \pm 7.96$ \\
L1-NB distance $(\mathrm{mm})$ & $8.36 \pm 2.63$ \\
L1-NB inclination $\left(^{\circ}\right)$ & $31.82 \pm 6.04$ \\
SNA $\left(^{\circ}\right)$ & $82.01 \pm 3.87$ \\
SNB $\left({ }^{\circ}\right)$ & $79.45 \pm 3.75$ \\
Wits $(\mathrm{mm})$ & $0.82 \pm 2.1$ \\
\hline
\end{tabular}

and U1-NA $\left({ }^{\circ}\right)(r=-0.489, P=0.005 ; P<0.05)$, SNB and overjet $(-0.469, P=0.008 ; P<0.05)$, and SNB and L1-NB $(\mathrm{mm})(r=-0.436, P=0.014 ; P<0.05)$ in Class III skeletal malocclusion in this study. However, there is no significant correlation between SNA and Wits in all three classes $(P=0.588, P>0.05 ; P<0.05)$, as can be seen in Table 4.

\section{Discussion}

In this study, there is no significant correlation between SNA and Wits in all three classes of malocclusion. According to Altman, ${ }^{[14]}$ the agreement value could be interpreted as intermediate. This means that most sample in this study had a quite similar condition between molar relation and the ANB angle. However in the reality, molar relations might not be in accordance with their skeletal conditions. Among the factors that must be evaluated to formulate a correct diagnosis and suitable treatment plan, the anteroposterior relationship between the jaws is a particularly relevant parameter. ${ }^{[15]}$ In Class I skeletal malocclusion in this study, there is only a correlation between SNA and U1-NA ( $\mathrm{mm})$, SNB and U1-NA ( $\mathrm{mm})$, and ANB and L1-NB (mm). This might be because the subject of Class I malocclusion is less harmonic and exposed to greater variations as compensation, both from the sagittal and vertical directions; thus, it is difficult to

\begin{tabular}{lc}
\hline $\begin{array}{l}\text { Table 2: The descriptive } \\
\text { malocclusion }\end{array}$ & statistic Class II skeletal \\
\hline Measurement & Mean \pm standard deviation \\
\hline Overjet $(\mathrm{mm})$ & $5.97 \pm 3.16$ \\
Overbite $(\mathrm{mm})$ & $3.61 \pm 1.88$ \\
U1-NA distance $(\mathrm{mm})$ & $8.37 \pm 4.05$ \\
U1-NA inclination $\left(^{\circ}\right)$ & $27.42 \pm 9.41$ \\
L1-NB distance $(\mathrm{mm})$ & $11 \pm 4.08$ \\
L1-NB inclination $\left(^{\circ}\right)$ & $34.62 \pm 6.45$ \\
SNA $\left(^{\circ}\right)$ & $82.7 \pm 4.01$ \\
SNB $\left(^{\circ}\right)$ & $75.83 \pm 4.09$ \\
ANB $\left(^{\circ}\right)$ & $6.85 \pm 2.25$ \\
Wits $(m m)$ & $4.26 \pm 3.33$ \\
\hline
\end{tabular}

\begin{tabular}{lc}
\hline $\begin{array}{l}\text { Table 3: The descriptive statistic of Class III skeletal } \\
\text { malocclusion }\end{array}$ \\
\hline Measurement & Mean \pm standard deviation \\
\hline Overjet $(\mathrm{mm})$ & $-0.29 \pm 2.08$ \\
Overbite $(\mathrm{mm})$ & $-0.31 \pm 2.11$ \\
U1-NA distance $(\mathrm{mm})$ & $10.69 \pm 4.22$ \\
U1-NA inclination $\left(^{\circ}\right)$ & $34.98 \pm 6.43$ \\
L1-NB distance $(\mathrm{mm})$ & $7.25 \pm 2.66$ \\
L1-NB inclination $\left(^{\circ}\right)$ & $25.94 \pm 6.61$ \\
SNA $\left({ }^{\circ}\right)$ & $80.29 \pm 3.91$ \\
SNB $\left(^{\circ}\right)$ & $83.34 \pm 3.62$ \\
ANB $\left(^{\circ}\right)$ & $-3.04 \pm 2.8$ \\
Wits $(m m)$ & $-4.93 \pm 7.1$ \\
\hline
\end{tabular}


Ardani, et al.: Correlation between skeletal and dental malocclusion in ethnic Javanese

Table 4: The result of Cohen's Kappa test showing the level of agreement between malocclusion class of molar relation and skeletal. The correlation between anteroposterior molar relation and ANB angle

\begin{tabular}{lccccc}
\hline Molar relation & \multicolumn{3}{c}{ ANB } & \multirow{2}{*}{$\boldsymbol{P}$ value } & Chance of agreement \\
\cline { 2 - 5 } & Class I & Class II & Class III & Total & \\
\hline Class I & $41(38.64 \%)$ & $13(37.88 \%)$ & $9(23.48 \%)$ & $63(100 \%)$ & 0.588 \\
Class II & $8(18.18 \%)$ & $35(79.54 \%)$ & $1(2.27 \%)$ & $44(100 \%)$ & $73.48 \%$ \\
Class III & $2(8 \%)$ & $2(8 \%)$ & $21(84 \%)$ & $25(100 \%)$ & \\
Total & $51(47.73 \%)$ & $50(33.33 \%)$ & $31(18.94 \%)$ & $132(100 \%)$ & \\
\hline
\end{tabular}

Significant if $P<0.05$

predict the entity. ${ }^{[15]}$ In a study by Hasegawa et al. ${ }^{[16]}$ in Mongolian population, there is a significant positive correlation between overjet and overbite and between L1-NB (mm) and U1-NA $\left({ }^{\circ}\right)$. It is in accordance with the result in this study.

Meanwhile, in Class II skeletal malocclusion, a negative significant correlation is found between the U1-NA $\left(^{\circ}\right)$ and Wits. This means that when the U1-NA $\left({ }^{\circ}\right)$ increases or proclination, the value of Wits will be decreased and vice versa. According to Tanaka et al. ${ }^{[17]}$ the position of occlusal plane used as a reference line for Wits measurement is influenced by the maxillary dentition growth and the inclination of occlusal plane is strongly affected by dentoalveolar bone growth. This study also exposes a negative significant correlation between SNB and Wits in Class II skeletal malocclusion, which shows that if the SNB decreases then the Wits value will increases and vice versa. It states that in Class II malocclusion patients with a more retruded mandibular position as compared to the cranial base, there is a possibility of an increase in Wits. ${ }^{[18]}$ A significant correlation is also discovered between Wits and ANB. The same result is also recognized in a study by Al-Jabba and Aldrees, ${ }^{[9]}$ which examined the relationship of molar, ANB, and Wits.

Furthermore, previous studies have discussed the relationship between ANB and overjet, where in the case of Class II skeletal malocclusions with large ANB values, the overjet can be a good predictor. It was also stated in a study by Zupancic et al. ${ }^{[1]}$ that there is a significant positive correlation between the overjet to ANB. Overjet can be used as a predictor of skeletal relationships only in Class II division I malocclusions, whereas for other types of malocclusion, the result is not predictable. However, in this study, the result is different from the previous studies. This might be due to the characteristics of Javanese patients whose most common case is bimaxillary protrusion.

Moreover, a correlation between skeletal and dental measurements in Class III skeletal malocclusion patients in this study tells a negative correlation between overjet and SNB. This shows the characteristics of patients with Class III skeletal malocclusion if the overjet decreases. It is likely due to the increase of SNB leading to Class III skeletal malocclusion. This study expresses a positive correlation between overjet and ANB. A study by Jabbar and Amjad ${ }^{[19]}$ on Class III malocclusion patients in Pakistan showed a similar result. They found that there is a positive significant correlation between ANB and overbite. This means that in Class III skeletal malocclusion patients, when the ANB decreases, the overbite also decreases. It is in accordance with a study by Zere et al., ${ }^{[20]}$ in which the mandibular prognathism is accompanied by a long face. Additionally, the correlation test shows a negative correlation between ANB and U1-NA $\left(^{\circ}\right)$. In Class III skeletal malocclusion with of the declined ANB, it is likely to be accompanied by proclination of the maxillary incisor that is consistent with the characteristics of Class III malocclusion in the study conducted by Li et al. ${ }^{[7]}$ in Chinese population. Finally, a positive significant correlation between ANB and L1-NB $\left({ }^{\circ}\right)$ is also found in this study. In recent study, Class III malocclusion is divided into three classes based on their characteristics and one of them showed a characteristic of retroclined mandibular incisor. ${ }^{[2]}$ This experiment was limited among Javanese ethnic samples and it did not distinguish the gender of the subject. Further experiment distinguishing the gender of the sample is expected.

\section{Conclusion}

It can be concluded from this study that in Class I skeletal malocclusion, there is correlation between SNA and U1-NA (mm), SNB and U1-NA (mm), ANB and L1-NB $(\mathrm{mm})$. However, in Class II skeletal malocclusion, there is a correlation between Wits and U1-NA $\left({ }^{\circ}\right)$, ANB and U1-NA $(\mathrm{mm})$, and ANB and U1-NA $\left(^{\circ}\right)$. In addition, in Class III skeletal malocclusion, ANB is correlated with overjet, overbite, U1-NA $\left({ }^{\circ}\right)$, and L1-NB $\left({ }^{\circ}\right)$. The correlations between SNA and U1-NA (mm), SNA and U1-NA $\left(^{\circ}\right)$, SNB and overjet, and SNB and L1-NB (mm) are also discovered in Class III skeletal malocclusion. The orthodontist should be aware of these findings and should be considered during diagnosis and treatment planning. Further study is required for confirmation with better setting and control.

\section{Ethical policy and institutional review board statement}

Ethical approval for the project was obtained from ethical clearance commitee of the Faculty of Dental Medicine, Airlangga University, Surabaya, Indonesia with number 270/HRECC.FODM/X/2018). 


\section{Acknowledgement}

We would like to thank the Faculty of Dental Medicine and Dental Hospital of Universitas Airlangga, Surabaya, East Java, Indonesia.

\section{Financial support and sponsorship} Nil.

\section{Conflicts of interest}

There are no conflicts of interest.

\section{REFERENCES}

1. Tak M, Nagarajappa R, Sharda AJ, Asawa K, Tak A, Jalihal S, et al. Prevalence of malocclusion and orthodontic treatment needs among 12-15 years old school children of Udaipur, India. Eur J Dent 2013;7:S45-53.

2. Kusuma ARP. Mouth breathing as risk factor and etiology of malocclusion. Majalah Ilmiah Sultan Agung 2010;48:1-19.

3. Alam MK. A to Z Orthodontics. Vol. 3. Kelantan, Malaysia: PPSP Publication; 2012. p. 20-5.

4. Mageet AO. Classification of skeletal and dental malocclusion: Revisited. Stoma Edu J 2016;3:40.

5. Perinetti G, Contardo L. Reliability of growth indicators and efficiency of functional treatment for skeletal class ii malocclusion: Current evidence and controversies. BioMed Res Inter 2017;1367691.

6. Uribe LMM, Sara CH, Colleen K, Kaci CV, Deborah VD, Thomas ES. Phenotypic diversity in Caucasian adults with moderate to severe class ii malocclusion. Am J Orthod Dentofacial Orthop 2014; 145:305-7.

7. Li C, Sihui YC, Fengshan CC. Classification and characterization of class III malocclusion in Chinese individuals. Head Face Med $2016 ; 12$.
8. Ardani IG, Kannayyah D, Triwardhani A. Correlation of maxillary and mandibular arch form and tooth size ratio in ethnic Javanese malocclusion patient. J Int Oral Health 2019;11:75-9.

9. Al-Jaba AH, Aldrees AM. ANB, wits and molar relationship: Do they correlate in orthodontic patients? Dentistry 2014;4:240.

10. Zhou Z, Liu F, Shen S, Shang L, Shang L, Wang X. Prevalence of and factors affecting malocclusion in primary dentition among children in Xi'an, China. BMC Oral Health 2016;16:91.

11. Zupancic S, Pohar M, Farcnik F, Ovsenik M. Overjet as a predictor of sagittal skeletal relationships. Eur J Orthod 2008;30:269-73.

12. Ardani IGAW, Maria LS, Jusuf S. Cephalometric characteristic of skeletal class II malocclusions in Javanese population at Universitas Airlangga Dental Hospital. Contemp Clin Dent 2018;9:342-6.

13. Ardani IGAW, Willyanti I, Narmada IB. Correlation between vertical components and skeletal Class II malocclusion in ethnic Javanese. Clin Cos Invest Dent 2018:10:297-302.

14. Altman DG. Practical Statistics for Medical Research. London, UK Chapman and Hall; 1991. p. 1-661.

15. Lombardo L, Sgarbanti C, Guarneri A, Siciliani G. Evaluating the correlation between overjet and skeletal parameters using DVT. Int J Dent 2012;2012:921-42.

16. Hasegawa Y, Ezura A, Nomintsetseg B. The relationship between the incisor position and lingual surface morphology in normal occlusion. Odontology 2017;105:84-90.

17. Tanaka EM, Sato S. Longitudinal alteration of the occlusal plane and development of different dentoskeletal frames during growth. Am J Orthod Dentofacial Orthop 2008;134:602e1-11.

18. Hedayati Z, Heidari S, Khaje F. Evaluation of correlation between Wits' appraisal and a new method for assessment of sagittal relationship of jaws. Prog Orthod 2013;15:41.

19. Jabbar A, Amjad M. Correlation of overjet, ANB, and Wits appraisal for assessment of sagittal skeletal relationship. Pakistan Ortho J 2012;4:17-23.

20. Zere E, Chaudhari PK, Sharan J, Dhingra K, Tiwari N. Developing class III malocclusions: Challenges and solutions. Clin Cosmet Investig Dent 2018;10:99-116. 